Dossiê Especial: Experiências do PIBID na formação inicial e continuada de professores de

línguas estrangeiras

HIBARINO \& NODARI (orgs)

Revista X, vol.1, 2015

\title{
A INFLUÊNCIA DO PIBID-INGLÊS NA FORMAÇÃO INICIAL DO PROFESSOR
}

The Influence of English PIBID in the Initial Development of the Teacher

\author{
Cassiana Bittencourt MUSHASHE ${ }^{1}$ \\ Gisele dos Santos da SILVA ${ }^{2}$
}

\begin{abstract}
Resumo: O presente trabalho tem como objetivo relatar nossa experiência como graduandas do curso de Letras Português/Inglês da Universidade Tecnológica Federal do Paraná e bolsistas do Programa Institucional de Bolsa de Iniciação à Docência (PIBID) de Língua Inglesa e de que forma essa experiência refletiu em nossa formação inicial na carreira docente. Para tanto, primeiramente, descreveremos como se deu o processo de leitura, discussão, preparação e divisão dos bolsistas ainda na Universidade, durante o primeiro semestre do projeto, antes de começarem seus trabalhos devidamente em sala de aula. Em seguida, focaremos em nossa prática de trabalho com gêneros textuais, embasada principalmente na teoria bakhtiniana de gêneros discursivos (BAKHTIN, 1997), em consonância com as considerações acerca dos gêneros textuais apresentadas por Bazerman e Miller (2011) e a proposta de sequência didática de Schneuwly e Dolz (2004). Por fim, traremos uma reflexão acerca da nossa atuação enquanto bolsistas de iniciação à docência no PIBID e como a experiência de participar do projeto contribuiu naquele momento para nossa formação docente inicial.

Palavras-chave: PIBID; Língua inglesa; Formação inicial docente.
\end{abstract}

\begin{abstract}
This paper aims to present our experience as undergraduate students of Letters course at Federal Technologic University of Paraná and participants of Teaching Initiation Scholarship Program (PIBID), from English subject, and how it influences/reflects our development as teachers. Firstly, we are going to describe how the literature review, discussions, preparation and division of the undergraduate students were conducted at the University during the first semester of the project before we start to work in class. Afterwards, we are going to focus on our practice working with textual genres, based on Bakhtin's theory of discursive genres (BAKHTIN, 1997), in accordance with considerations about textual genres presented by Bazerman and Miller (2011) and the proposed didactic model by Schneuwly and Dolz (2004). Finally, we are going to reflect about our practice as teaching initiation scholarships and how PIBID's experience contributed at that moment to our initial development as teacher.
\end{abstract}

Keywords: PIBID; English language; Pre-service teacher education.

\section{Introdução}

Este relato de experiência é resultado da prática obtida enquanto bolsistas do Programa Institucional de Bolsa de Iniciação à Docência - PIBID - financiado pela CAPES, cujo

\footnotetext{
${ }^{1}$ Licenciada em Letras Português-Inglês pela UTFPR. gisele2604@gmail.com.

${ }^{2}$ Mestranda em Estudos Linguísticos pela UFPR. cassianabtt@gmail.com.
} 
Dossiê Especial: Experiências do PIBID na formação inicial e continuada de professores de línguas estrangeiras

HIBARINO \& NODARI (orgs)

Revista X, vol.1, 2015

objetivo é auxiliar na formação de futuros professores, incentivando a carreira docente dos alunos de cursos de licenciatura, além de aproximar o ensino básico do ensino universitário 3 . O projeto do PIBID de Língua Inglesa da Universidade Tecnológica Federal do Paraná (UTFPR) teve o seu primeiro grupo formado em 2011 e suas atividades foram desenvolvidas em duas escolas estaduais de Curitiba entre 2011 e 2012. Para esse trabalho, descreveremos como se deu o processo de preparação, reflexão e acompanhamento das aulas em turmas da Escola Estadual Conselheiro Carrão e do Colégio Estadual Professor Elias Abrahão, ambos localizados na cidade de Curitiba - PR.

Desde o início do PIBID de Inglês na UTFPR, uma das principais questões a serem estudadas pelos bolsistas era o desenvolvimento do interesse dos alunos pelas aulas de inglês assim como o planejamento de uma prática que fosse significativa para cada aluno, tornando a aula de inglês mais atrativa e importante para cada grupo com os quais estaríamos em contato durante a execução do projeto. Essa preocupação surgiu dos relatos dos professores regentes de ambas as escolas, que percebiam a falta de interesse dos alunos do ensino básico pela disciplina de língua inglesa. Os professores regentes buscavam acreditavam que a participação do projeto do PIBID-Inglês poderia auxiliá-los na busca de alternativas para tornar as aulas de inglês mais profícuas. Sendo assim, após um semestre de pesquisas bibliográficas relacionadas ao ensino/aprendizagem de língua inglesa e a preparação de seminários sobre as políticas educacionais brasileiras - Diretrizes Curriculares do Estado do Paraná (PARANÁ, 2008), Parâmetros Curriculares Nacionais (BRASIL, 2006) e Orientações Curriculares Nacionais (BRASIL, 2006), doravante DCE, PCN e OCN -, bem como a realização de observações em diversas turmas de ambas as escolas para conhecer e se ambientar, a etapa seguinte consistiu na atuação propriamente dita em sala de aula. Durante o primeiro ano do projeto ficou decidido que os 12 alunos bolsistas da graduação trabalhariam em duplas.

Sendo assim, primeiramente explanaremos mais detalhadamente como teve início o primeiro grupo do Programa Institucional de Bolsa de Iniciação à Docência de Língua Inglesa na UTFPR, e quais eram os objetivos do grupo. Em seguida, vamos nos deter no relato de nossa experiência enquanto bolsistas do PIBID e qual foi o impacto desse projeto em nossa formação docente inicial. Por fim, em nossas considerações finais, faremos uma célere reflexão acerca de todo esse processo.

\footnotetext{
${ }^{3}$ Informações retiradas de: http://www.capes.gov.br/educacao-basica/capespibid. Acesso em 20/05/2014.
} 


\section{Dossiê Especial: Experiências do PIBID na formação inicial e continuada de professores de línguas estrangeiras \\ HIBARINO \& NODARI (orgs) \\ Revista X, vol.1, 2015}

\section{O PIBID-Inglês UTFPR}

No Edital Capes PIBID-2009, a UTFPR aprovou um Projeto Institucional de Iniciação à Docência composto por 6 subprojetos, dentre eles o projeto do PIBID-Português que contemplava o curso de Licenciatura em Letras Português-Inglês do Câmpus Curitiba. No ano de 2011, após ser aprovado pela CAPES, iniciou-se também o projeto para a disciplina de Inglês. O PIBID-Inglês deu início às suas atividades no segundo semestre de 2011, com um grupo composto por doze discentes do curso de Letras de períodos diferentes, dois professores supervisores de escolas públicas da região de Curitiba e a professora coordenadora. Primeiramente, os alunos foram separados em duplas para desenvolverem seus trabalhos. As duplas acompanhariam as aulas de inglês no Colégio Estadual Elias Abrahão e no Colégio Estadual Conselheiro Carrão, ambos localizados em Curitiba.

O projeto do PIBID-Inglês da UTFPR tinha por objetivo a formação de professores a partir da perspectiva de ensino de inglês como língua internacional (CRYSTAL, 2010), considerando as questões epistemológicas, filosóficas, políticas e culturais que subjazem essa concepção. Tais questões constituíram o prisma através do qual foram avaliados criticamente os documentos que regulamentam o ensino nas escolas DCE (PARANÁ, 2008), PCN (BRASIL, 2006) e OCN (BRASIL, 2006), sob a finalidade última de subsidiar teoricamente o plano de ação.

As atividades do PIBID tiveram início com a fase de estudo pelos bolsistas graduandos e pelos professores do Ensino Básico, doravante EB, participantes. Ocorriam reuniões semanais com todos os integrantes do projeto para apresentação dos tópicos, leituras, discussões e questionamentos relacionados aos desafios que encontraríamos em sala de aula.

Após cerca de seis meses de contato próximo com as realidades das escolas parceiras, com visitas e observações, no primeiro semestre de 2012 as duplas foram distribuídas entre as duas escolas e cada par trabalharia em uma turma fixa. Assim, cada escola recebeu três duplas em turmas diferentes. Após um primeiro contato com a turma em que atuaríamos, passamos a frequentar uma vez por semana a escola e auxiliar em sala de aula nas atividades feitas pelo professor regente da turma, e também com atividades extras quando percebíamos alguma dificuldade específica por parte dos alunos.

As reuniões ocorriam paralelamente ao trabalho feito em sala, o que auxiliava a esclarecer nossas dúvidas, a preparar o material para os alunos, trocar relatos e experiências, além de trocar informações a respeito do que estava sendo feito nas duas escolas. Sendo 
Dossiê Especial: Experiências do PIBID na formação inicial e continuada de professores de línguas estrangeiras

HIBARINO \& NODARI (orgs)

Revista X, vol.1, 2015

assim, permanecemos ao longo de um semestre na turma de $1^{\circ}$ ano do Ensino Médio no Colégio Estadual Conselheiro Carrão. A presença dos professores regentes nas reuniões desde o início do projeto foi fundamental, pois nos proporcionou oportunidade de discutir, contrapor e relacionar a teoria com a prática da sala de aula.

Desde o começo da nossa atuação em sala, do dia 05 de março de 2012 até 18 de junho de 2012, registramos nossas experiências em um Diário de Bordo online com acesso restrito aos integrantes do PIBID-Inglês da UTFPR. Naquele espaço contávamos um pouco sobre a nossa experiência em sala de aula de forma bem reflexiva e pessoal, o que tínhamos planejado, o que poderíamos melhorar, os pontos positivos e negativos da nossa prática. Também colocávamos o material utilizado em sala, caso mais alguma dupla tivesse interesse em utilizar ou modificar o material produzido. E para registrar e formalizar as reuniões, um integrante do grupo ficava responsável por redigir uma memória.

\section{O PIBID e a sala de aula: uma experiência da teoria à prática}

\subsection{Refletindo sobre a teoria}

Como já fora mencionado, no primeiro semestre nós assistimos cerca de 18 aulas de inglês nas duas escolas para entrarmos em contato com os alunos e com os espaços. Simultaneamente, durante as reuniões em grupo, lemos e discutimos os documentos orientadores do ensino do Brasil (PCN, OCN) e do Paraná (DCE) visando conhecer o que se espera da disciplina de inglês nas escolas públicas do país. Após conhecermos a turma de $1^{\circ}$ ano do Ensino Médio na qual atuaríamos, elaboramos um projeto a ser trabalhado, o qual deveria condizer com a série e o conteúdo curricular da disciplina que o professor regente da turma estava trabalhando.

Sendo assim, considerando como cenário o mundo globalizado em que o inglês é a principal língua estrangeira de contato, e pensando em como essa língua poderia ser significativa no contexto em que aquele grupo de alunos se encontrava, buscamos enfatizar a importância da língua (no caso, a língua inglesa) para a comunicação. Para isso, o trabalho com a língua não poderia contemplar apenas atividades gramaticais ou o uso de textos como pretexto para exercícios estruturalistas que não atendam o propósito comunicativo.

Posto isso, tendo em vista a concepção de linguagem como processo de interação apresentada, optamos por uma proposta de trabalho calcada nos gêneros textuais, uma vez que o uso da língua permite a produção de "tipos relativamente estáveis" de enunciados que 


\section{Dossiê Especial: Experiências do PIBID na formação inicial e continuada de professores de línguas estrangeiras \\ HIBARINO \& NODARI (orgs) \\ Revista X, vol.1, 2015}

circulam em diferentes esferas sociais permitindo a comunicação entre os indivíduos. A esses tipos de enunciados relativamente estáveis Bakhtin (1997) dá o nome de gêneros discursivos. Para Bakhtin (1997), a língua é um fator social que permite a interação verbal e a ação no mundo. Dessa noção surge a perspectiva de ensinar a língua como uma prática social que se materializa por meio de enunciados (discursos), pelos quais o sujeito age e interage em seu contexto social. Logo, os gêneros textuais são formas de enunciados intermediárias da prática de linguagem no contexto social, e para o aluno poder interagir com seu contexto, ele precisa ter certo domínio dos gêneros textuais que circulam em sua realidade social. Com isso, podemos concluir que aprender uma língua só tem sentido se tiver uma função real e social para o aprendiz, de maneira que este possa utilizá-la em diferentes contextos visando à comunicação com seus interlocutores. Em meio a essa posição, cabe ao professor - tanto ao professor regente quanto ao professor em formação - fazer uma leitura crítica dos documentos que orientam sua prática pedagógica, como estar ciente de seu papel como mediador do conhecimento.

A concepção de gêneros discursivos como prática da linguagem na interação social proposta por Bakhtin (1997) aparece na fundamentação das DCE (PARANÁ, 2008) orientando o ensino de línguas como prática social nas escolas públicas do Paraná. De acordo com as Diretrizes Curriculares de Educação Básica de Língua Estrangeira,

O trabalho com a Língua Estrangeira Moderna fundamenta-se na diversidade de gêneros textuais e busca alargar a compreensão dos diversos usos da linguagem, bem como a ativação de procedimentos interpretativos alternativos no processo de construção de significados possíveis pelo leitor. (PARANÁ, 2008, p. 58).

Os PCN (BRASIL, 2006) também seguem a visão de linguagem como interação social e destacam a importância da língua estrangeira para a comunicação dos homens e o acesso ao conhecimento. Ressaltam a necessidade de domínio das 4 habilidades (compreensão oral e escrita, e produção oral e escrita) na língua estrangeira para a comunicação entre as diferentes culturas do mundo globalizado, mas apontam o uso de gêneros textuais para o ensino de Língua Portuguesa em específico.

Como o projeto do PIBID-Inglês da UTFPR se baseava na visão interacionista da linguagem, buscando priorizar os eventos comunicativos, o propósito do trabalho desenvolvido pelos graduandos-bolsistas era promover o ensino de língua de acordo com o contexto de uso e o papel dos aprendizes na situação social de comunicação. Sendo assim, os 
Dossiê Especial: Experiências do PIBID na formação inicial e continuada de professores de línguas estrangeiras

HIBARINO \& NODARI (orgs)

Revista X, vol.1, 2015

gêneros textuais poderiam ser utilizados na promoção da interação no ensino de línguas. Schneuwly e Dolz (1999) acreditam na hipótese de que "é através dos gêneros que as práticas de linguagem encarnam-se nas atividades dos aprendizes." (p. 6), pois são instrumentos que possibilitam a comunicação. Essa mesma concepção de gêneros textuais como instrumentos comunicativos é adotada por Bazerman e Miller (2011).

Para Bazerman e Miller (2011), “O gênero é uma ação retórica tipificada baseada numa situação retórica recorrente" (p.16). Sendo assim, a recorrência em situações retóricas se faz importante por permitir a tipificação de tais situações por meio de analogias ou semelhanças. Quando interpretamos uma situação nova, relacionando-a similar ou analogamente com outras situações, estamos tipificando essa ação retórica ao criar uma resposta para tal situação, que passa a fazer parte do conhecimento coletivo, permitindo que essa resposta seja aplicada em novas situações. Em outras palavras, é a tipificação proveniente da recorrência em situações retóricas que permite certa regularidade no conteúdo e na forma do discurso, resultando naquilo que classificamos como gêneros discursivos. Ou seja, a tipificação retórica da qual tratam Bazerman e Miller (2011) traz o mesmo entendimento apresentado por Bakhtin (1997) sobre gêneros do discurso ao considerá-los "tipos relativamente estáveis de enunciados".

Mediante essa visão, acreditamos que o uso de gêneros textuais no ensino de língua pode permitir não apenas o aprendizado das estruturas linguísticas, como também o uso adequado desta em contextos sociais efetivos, levando os alunos a se perceberem como agentes discursivos. Portanto, a escolha dos gêneros a serem aplicados em uma sequência didática em sala de aula também é uma tarefa importante, que exige do professor muita atenção e conhecimento de seu público-alvo, visto que, para haver um aprendizado satisfatório, os gêneros escolhidos devem ser significativos dentro da realidade social dos alunos.

De acordo com Schneuwly e Dolz (2004), a sequência didática é um utensílio para orientar os professores na realização de suas aulas e organizar a aprendizagem a partir de gêneros textuais, permitindo assim a ação em grupo. Em outras palavras, a sequência didática é um conjunto de atividades planejadas a partir de gêneros textuais para serem trabalhadas em determinado período de tempo, capacitando ao aluno o domínio do gênero de forma gradual. Posto isso, após o período de observação, verificamos o constante contato dos alunos com a tecnologia - durante toda a aula eles usavam seus aparelhos eletrônicos e comentavam sobre ferramentas virtuais. Durante a aula sobre o capítulo três do livro Upgrade - Volume 1, 
Dossiê Especial: Experiências do PIBID na formação inicial e continuada de professores de línguas estrangeiras

HIBARINO \& NODARI (orgs)

Revista X, vol.1, 2015

intitulado "Technology - Progress and Achievement", aproveitamos a ocasião para aplicar um questionário e conferir a relação do grupo com a tecnologia (anexo 1). Embora a maior parte dos alunos tivesse acesso à internet, nem todos estavam dispostos a participar de atividades online desenvolvidas por nós, levando-nos a entender que esses alunos ainda enxergavam a interação propiciada pela internet como forma de diversão e lazer, ou seja, algo que não cabe na sala de aula, conforme citaram no questionário, isto é, não como uma ferramenta para o aprendizado.

Trabalhamos com uma turma do $1^{\circ}$ ano do Ensino Médio, com alunos com idade entre 15 e 17 anos. Com essa faixa etária e nascidos até o ano 2000, podemos denominá-los pertencentes à "Geração Y", ou seja, é uma geração que convive cotidianamente e com desenvoltura com a tecnologia. Para essa geração digitalizada, os avanços e descobertas tecnológicas são acontecimentos comuns, com os quais tem facilidade de lidar (XAVIER, 2011). Aparentemente, os alunos que participaram desse trabalho apresentavam certo conforto em agir no ciberespaço. Dessa maneira, cogitamos a possibilidade de utilizar o gênero biografia aliado ao gênero da cibercultura "blog", este como possível atrativo no aprendizado da língua inglesa, já que o ciberespaço parecia satisfazer a maior parte dos estudantes, além de ser uma maneira de aproximar a prática de ensino em sala de aula dos interesses cotidianos dos alunos.

\subsection{Da teoria à prática: relatos de nossa experiência}

Durante o semestre que permanecemos em sala notamos que o professor regente da turma seguia o conteúdo do livro didático Upgrade - Volume 1. Este livro foi aceito e distribuído pelo PNLD de 2012, 2013 e 2014 como componente curricular de Língua Estrangeira Moderna - Inglês. Em sala, o professor regente utilizou as quatro primeiras unidades do livro, enquanto fazíamos algumas intervenções com atividades e auxílio aos alunos. As unidades trabalhadas foram as seguintes: "Unit 1 - Teen Matters" abordando conteúdo e vocabulário sobre família e emoções e o conteúdo linguístico do presente simples por meio de textos, tirinhas, diálogos, acróstico e outros materiais para consulta; "Unit 2 - The Earth - We still care!" discutindo as questões referentes ao aquecimento global com textos, dicas, pinturas, imagens e o presente contínuo; “Unit 3 - Technology - Progress and Achievements" fazendo com que os alunos dialogassem com gráficos, vocabulários relacionados à tecnologia, diferenciando celular e computadores, textos informativos e o 
Dossiê Especial: Experiências do PIBID na formação inicial e continuada de professores de línguas estrangeiras

HIBARINO \& NODARI (orgs)

Revista X, vol.1, 2015

ensino do tempo futuro e do imperativo; "Unit 4 - Different Eras, Different Idols" retomando personagens importantes da história por meio de linhas do tempo, biografias e textos para o uso do passado simples.

Em geral todo o grupo de bolsistas do PIBID começou suas intervenções apresentando e discutindo na primeira aula a importância do Inglês, por meio de uma apresentação em PowerPoint que trazia exemplos de como a língua inglesa se faz presente em nosso cotidiano, através de músicas, jogos, filmes, internet, etc. No nosso caso, essa discussão condizia muito bem com as questões trazidas no começo do livro didático, com uma série de perguntas sobre curiosidades de países de língua inglesa. Em uma atividade mais dinâmica em sala de aula, também procuramos conhecer melhor os alunos e a relação deles com a língua inglesa. As respostas foram bem diversificadas, revelando um desafio para o nosso trabalho, pois deveríamos ampliar o conhecimento daqueles que já tinham certo domínio e afinidade com a língua, e também despertar o interesse para o estudo e aprendizado de alunos mais afastados da língua inglesa. $\mathrm{O}$ momento inicial foi um misto de dúvidas, ansiedade e expectativa sobre a turma com a qual passaríamos um semestre e sobre como seria nossa interação com eles. Os alunos foram bem receptivos conosco, pois enquanto nas observações a turma ficava um pouco mais contida, nos momentos em que fazíamos intervenções e exercícios eles interagiam mais, perguntando sobre aspectos e usos da língua. Pouco a pouco, percebemos que a sala tornou-se um ambiente propício e profícuo para o desenvolvimento das atividades que levamos.

Da segunda aula em diante, participamos auxiliando o professor regente nas tarefas em sala e contribuindo com atividades de acordo com as necessidades da turma. Preparamos um exercício com frases embaralhadas para que os alunos colocassem na ordem correta, já que eles estavam apresentando dificuldades na ordenação dos elementos constituintes das frases. Entre as frases que utilizamos, elencamos alguns exemplos na ordem correta: a) "Paula doesn't live in Curitiba. She lives in São Paulo”; b) "William works as a waiter in a Brazilian restaurant”; c) "Ana and Jacob don't like soft drink. They prefer orange juice”; entre outras. Além de ordená-las, também pedimos que fizessem a leitura das frases. A turma revelou-se bastante participativa ao opinar e contribuir tanto com o andamento das discussões dos temas iniciais de cada unidade do livro, assim como também na realização das atividades. Em uma das aulas sobre o aquecimento global, o texto apresentava a marcação da temperatura em escala Fahrenheit, logo o professor foi questionado sobre as escalas de medidas adotadas em 
Dossiê Especial: Experiências do PIBID na formação inicial e continuada de professores de línguas estrangeiras

HIBARINO \& NODARI (orgs)

Revista X, vol.1, 2015

países como Estados Unidos e Inglaterra, dando início a uma interessante discussão a respeito das medidas de temperatura adotadas em diferentes países.

Nas ocasiões anteriores e posteriores às provas, acompanhamos o sentimento dos alunos e do professor regente. Quando os resultados não atingiam as expectativas, elaborávamos exercícios para ajudar a prepará-los para a prova de recuperação da nota. $\mathrm{O}$ professor também auxiliava corrigindo a prova em sala, e destacando os pontos principais.

Em uma das aulas sobre o Present Continuous, na qual levamos um vídeo e uma atividade de mímica, ficou evidente a preferência dos alunos por atividades mais dinâmicas. A exibição do vídeo contemplava ações no presente contínuo; após exibi-lo, perguntamos aos alunos quais ações eles recordavam, e eles lembravam a maior parte delas. E, com relação à mímica, dividimos a turma em dois grupos e, embora receosos no começo, a participação e empolgação dos alunos cresceu gradativamente enquanto precisavam encenar e adivinhar frases interrogativas e afirmativas representando ações em progresso sorteadas. Com essa atividade, procuramos simular a utilização da língua inglesa em uso cotidiano, tentado levar os alunos a refletirem sobre o uso real da língua, fugindo um pouco das atividades do tipo 'livro e caderno'. Acreditamos que a diversificação de atividades contribuiu para manter os alunos atentos, pois com a mudança de atividade os alunos também mudavam o foco de atenção, como se recomeçassem um ciclo novo. Também porque eles se perceberam como agentes responsáveis pela execução do exercício e isso foi reforçado na atividade de mímica quando o grupo dependia da gesticulação e focava toda a atenção em um aluno, tentando atribuir sentido àquilo que estavam fazendo e utilizando a língua inglesa para a comunicação.

Também realizamos alguns exercícios com os alunos em duplas, como a descrição de imagens em que poderiam empregar o presente contínuo e um quiz envolvendo questões sobre a prática da reciclagem. Mesmo com os diferentes ritmos, os alunos trabalharam bem em dupla. Acreditamos que um dos motivos foi a menor exposição perante a turma e o maior conforto para participar da atividade com o colega. Muitas vezes a dificuldade em se expressar na língua estrangeira inibe alguns alunos que, quando ficam em duplas com alguém de seu grupo de afinidade, ficam mais à vontade para participar.

Finalmente, na aula da última unidade, aliamos o ensino de gênero biografia com a cibercultura do gênero blog. No início da "Unit 4 - Different Eras, Different Idols" do livro dos alunos havia uma atividade voltada para a biografia de Tarsila do Amaral, então decidimos preparar uma sequência didática com o gênero biografia e, posteriormente, com o gênero post em blog. Assim, além da biografia trazida pelo livro, juntamente com os alunos e 
Dossiê Especial: Experiências do PIBID na formação inicial e continuada de professores de línguas estrangeiras

HIBARINO \& NODARI (orgs)

Revista X, vol.1, 2015

com o auxílio de uma apresentação em PowerPoint preparada por nós, fizemos a modelização do gênero, apresentamos alguns suportes em que uma biografia pode ser veiculada e levamos mais um exemplo de biografia de alguém que seria familiar a todos: o jogador de futebol Ronaldo (anexo 2). Após a leitura e discussão sobre o gênero, entregamos o enunciado da produção escrita (anexo 3), segundo o qual os alunos escreveram suas próprias biografias. Enquanto produziam seus textos, nós passávamos de carteira em carteira para auxiliá-los. Esse foi um momento crucial tanto para nós, professoras em formação, quanto para os alunos, pois vários destes alegaram no início da atividade que não tinham nada a escrever, que não tinham feito nada de significante em suas vidas, mas conforme foram escrevendo, perceberam que cada um tem uma história, tem um papel no grupo social de que participa. Por outro lado, para nós aquela atividade permitiu que conhecêssemos melhor aqueles alunos e também compreendêssemos muitas de suas atitudes em sala de aula.

$\mathrm{Na}$ aula seguinte, trabalhamos com o post em blog, em que os alunos foram ao laboratório de informática e postaram suas biografias em um blog privado criado para acesso somente da turma. A intenção dessa atividade era, além de interagir com o ciberespaço, que os alunos se conhecessem melhor através do blog da turma, pois durante esse semestre percebemos que dentro da turma os alunos se dividiam em grupos, seja por afinidade ou gostos semelhantes, e que grande parte não interagia com o restante dos colegas e em alguns casos nem sabiam o nome dos outros colegas. Pretendíamos continuar com essa atividade na aula seguinte, mas descobrimos que aquela seria nossa última aula com a turma, pois na semana seguinte entrariam em férias. Mesmo assim, o retorno que tivemos dos alunos foi bastante positivo e o laço afetivo que criamos com o grupo foi muito aprazível.

Entre os trabalhos que desenvolvemos, podemos mencionar a organização, separação e elaboração de materiais para serem usados em sala, tais como: a criação de frases que correspondessem às imagens, a ordenação de palavras soltas formando frases, exercícios com música, trabalho com vídeo para ilustrar o tempo verbal da aula, mímica e quiz. Geralmente procurávamos criar atividades que fossem envolver os alunos e estivessem de acordo com o conteúdo trabalhado, de forma que fossem, além de interessantes, também significantes, isto é, que os alunos vissem um sentido no uso da língua inglesa em contextos reais.

\subsection{O PIBID e a formação inicial do professor}


Dossiê Especial: Experiências do PIBID na formação inicial e continuada de professores de

línguas estrangeiras

HIBARINO \& NODARI (orgs)

Revista X, vol.1, 2015

A participação no PIBID contribui de forma muito positiva e fundamental para nossa formação docente. Tivemos o apoio na Universidade, dos colegas e professores, e também na escola, com a equipe pedagógica e o professor regente, para nos auxiliar com dúvidas e passar um pouco mais de segurança na hora da nossa prática. $\mathrm{O}$ embasamento teórico e as reuniões foram essenciais na reflexão do que é ser professor, qual é o seu papel em sala de aula, o que pode ser feito para ensinar a língua de maneira efetiva e significativa e quais realidades enfrentaríamos em cada turma nas duas escolas.

A experiência de passar um semestre em sala também nos aproximou do cotidiano de um professor e dos alunos do EB, revelando uma experiência bem próxima do real e daquela que vivenciaríamos após a formação acadêmica. O PIBID proporcionou um espaço de construção e aprimoramento da prática docente dos graduandos-bolsistas, pois a relação e a participação nas escolas aconteceram de forma colaborativa e com maior contato com cada situação de ser professor.

No entanto, com o passar do tempo e com a convivência com aqueles alunos nós, professoras em formação, percebemos que não estávamos ali para fazer grandes mudanças, mas sim para transformarmo-nos e ressignificar-nos juntamente com aquele grupo de alunos. A escola é um espaço de reflexão e de construção de conhecimento e o professor não é o ditador do que é certo ou errado; pelo contrário, o professor está ali para ajudar os alunos a enxergarem as várias lentes que circundam a sociedade em que vivem e a pluralidade de escolhas possíveis, cabendo a cada um escolher o que é mais adequado para si em cada contexto. Nesse sentido a língua inglesa seria mais uma forma pela qual o aluno poderia agir e interagir não só com o seu contexto social, como também poderia expandir sua esfera interacional com outros grupos socioculturais, alcançando o objetivo maior do ensino de língua inglesa nas escolas públicas brasileiras: a comunicação. E novamente o papel do professor é criar possibilidades junto com os alunos - possibilidades de reflexão, de interação, de percepção da realidade e de construção de conhecimento - tudo isso mediado pela língua.

Outro aspecto que refletiu bastante em nossa formação foi a importância de conhecer nossos alunos para que haja um ambiente eficiente de trocas e aprendizagem. Com essa relação mais próxima com uma turma proporcionada pelo PIBID, constatamos que quando o professor conhece melhor seus interlocutores ele tem mais facilidade em direcionar suas atividades em sala de aula de acordo com o que parece ser relevante para os sujeitos do grupo. Além disso, quando o professor dá voz ao aluno, abrindo espaço para o aluno agir e participar, este consegue se colocar como sujeito de uma interação e aprender participando, 
Dossiê Especial: Experiências do PIBID na formação inicial e continuada de professores de línguas estrangeiras

HIBARINO \& NODARI (orgs)

Revista X, vol.1, 2015

negociando significados com o professor e com o grupo. Em outras palavras, o professor deve se perceber e levar os alunos a notarem também que ele não é o dono da verdade, mas que está ali para juntos buscarem sentidos para suas relações de convívio social.

A participação no PIBID também foi determinante em nossa escolha pela carreira docente inicial. Muitos graduandos, mesmo estando cursando licenciatura em Letras, sentemse pávidos por ter que ir para a sala de aula, dadas as condições educacionais brasileiras de que temos notícias diariamente. O PIBID permite, então, que o professor em formação inicial tenha maior contato com a realidade das salas de aula ao mesmo tempo em que há o apoio da universidade, do professor regente e da escola, ou seja, você tem um espaço para agir e tem onde buscar apoio, adaptando-se gradativamente ao ambiente escolar e podendo recorrer em caso de ajuda. Poderíamos dizer que o PIBID mostra o caminho e dá suporte para um primeiro contato com uma situação que mais tarde enfrentaremos sozinhos quando graduados.

\section{Considerações finais}

Acreditamos que parte do sucesso das atividades realizadas em sala, tanto aquelas em que só auxiliávamos os alunos, quanto na sequência didática com os gêneros textuais explorados, encontra-se no laço afetivo estabelecido ao longo do semestre, já que deixamos de ser apenas duas estranhas acompanhando as aulas deles e passamos a assisti-los em classe durante as aulas, com atividades complementares e diálogo constante sobre as lições. Com a realização das atividades e principalmente com o trabalho sobre o gênero biografia, percebemos a influência de acontecimentos na história dos alunos que refletiam diretamente em seus comportamentos em sala de diferentes formas - havia casos de perda dos pais, pais separados, carência, conflitos familiares que influenciavam em suas atitudes no ambiente escolar, por exemplo.

Em especial, sobre a realização dessa atividade como fechamento do semestre, destacamos dois pontos principais. O primeiro, que ao mesmo tempo em que nos permitiu conhecê-los como sujeitos além da sala de aula e do conteúdo a ser ministrado, também revelou uma atividade importante para ser feita antes do fim do semestre, já que conhecer os alunos pode beneficiar o professor no direcionamento das atividades e no entendimento de individualidades. Entretanto, um segundo ponto a ser destacado é que se tivéssemos aplicado a sequência didática sobre biografia já nas primeiras aulas, talvez os alunos não estivessem tão à vontade para contar sobre a própria vida, pois ainda não tínhamos um laço afetivo 
Dossiê Especial: Experiências do PIBID na formação inicial e continuada de professores de línguas estrangeiras

HIBARINO \& NODARI (orgs)

Revista X, vol.1, 2015

propriamente estabelecido. Ou seja, cabe ao professor encontrar um meio termo, para que possa transmitir a confiança necessária aos alunos na realização da atividade e para que também possa usufruir e direcionar melhor a própria prática tendo em mente que algumas histórias podem surpreendê-lo e mudar a forma como enxerga a classe. Em outras palavras, notamos que cabe ao professor buscar conhecer melhor seus alunos, despertando uma relação de confiança mútua, com o objetivo de desenvolver a prática em sala de aula de acordo com as realidades destes.

Em conversa posterior ao fim do projeto na turma do $1^{\circ}$ ano, percebemos o quanto a convivência com o grupo de alunos do EB e o desenvolvimento das atividades supracitadas foi importante para nós, enquanto professoras, e para os alunos enquanto sujeitos. Assim como tivemos a oportunidade de nos aproximar deles e da realidade em que viviam, conhecendo um pouco da história de cada um, eles também puderam refletir sobre a própria identidade. Também puderam perceber que são sujeitos atuantes no mundo em que vivem, que também estão construindo a própria história a cada dia que passa e que a língua inglesa pode ser uma aliada nesse processo de construção do sujeito, permitindo-lhes ampliar seus horizontes interacionais e ajudando-os no desenvolvimento do conhecimento.

Enfim, o PIBID foi uma experiência de tamanha importância em nossa formação docente, refletindo não apenas em nossas escolhas, mas também no trabalho que desenvolvemos atualmente em sala de aula. Ensinar uma língua é abrir uma querela de possíveis caminhos a serem percorridos como sujeito que age por meio do discurso em diferentes contextos sociais. Ensinar não é dar respostas, é buscar construir conhecimentos a partir de sua realidade e de suas experiências junto com os alunos e reconhecer que nada é fixo, pronto, acabado. A língua muda, o conhecimento se transforma e cabe ao sujeito - aluno e professor - a busca constante pelo sentido daquilo que lhe é plausível. Como disse Paulo Freire, "O homem, como um ser histórico, inserido num permanente movimento de procura, faz e refaz constantemente o seu saber." (FREIRE, 1981, p. 47) e é nesse movimento de busca constante pelo conhecimento que damos sentido às nossas atitudes e à nossa existência.

\section{Agradecimento}

Agradecemos à CAPES pela concessão das bolsas PIBID que possibilitaram a realização desta pesquisa. 
Dossiê Especial: Experiências do PIBID na formação inicial e continuada de professores de línguas estrangeiras

HIBARINO \& NODARI (orgs)

Revista X, vol.1, 2015

\section{Referências}

BAKHTIN, M. Estética da criação verbal. 2a ed. São Paulo: Martins Fontes, 1997.

BAZERMAN, C. MILLER, C. Gêneros Textuais. [Bate-papo Acadêmico]. [Angela Paiva Dionísio, Carolyn Miller, Charles Bazerman, Judith Ho_ anagel (orgs.)]. E-Book. 1. ed. Recife: [s.n.], 2011.

BRASIL. Ministério da Educação. Orientações curriculares do ensino médio. Brasília, MEC, 2006.

BRASIL. Ministério da Educação. Parâmetros curriculares nacionais. Brasília, MEC, 2006.

CRYSTAL, D. English as a Global Language. (2.ed). Cambridge: Cambridge University Press, 2010.

FREIRE, P. Educação como prática da liberdade. Rio de Janeiro, Paz e Terra, 1981.

PARANÁ. Secretaria de Estado da Educação. Diretrizes Curriculares da Educação Básica. Língua Estrangeira Moderna. Curitiba: SEED, 2008.

SCHNEUWLY, B.; DOLZ, J. Gêneros orais e escritos na escola. Campinas, SP: Mercado de Letras, 2004.

Os gêneros escolares: das práticas de linguagem aos objetos de ensino. [Título original: Les genres scolaires: des pratiques langagières aux objets d'enseignement. - Trad. de Glaís Cordeiro]. IN: Revista Brasileira de Educação, no 11, Mai/Jun/Jul/Ago, 1999.

Upgrade / obra coletiva concebida, desenvolvida e produzida pela Richmond Educação; editora Gisele Aga. - São Paulo: Richmond Educação, 2010.

XAVIER, A. C. Letramento digital: impactos das tecnologias na aprendizagem da Geração Y. IN: Calidoscópio. Vol. 9, n 1, Pp. 3-14, jan/abr 2011. 
Dossiê Especial: Experiências do PIBID na formação inicial e continuada de professores de línguas estrangeiras

HIBARINO \& NODARI (orgs)

Revista X, vol.1, 2015

ANEXOS

\section{ANEXO 1}

\section{Questionário sobre o uso da internet pelos alunos}

Onde você geralmente acessa a internet? Com qual frequência? Por quantas horas?

1) Quais são os sites que você mais utiliza (ex.: redes sociais, e-mail, site de pesquisa, vídeo, jornal/revista online, etc)?

2) Você costuma fazer download? Quais tipos de materiais vocês costuma fazer download?

3. Dos itens abaixo, quais você utiliza com mais frequência?
a) ( )Facebook
b) ( )Orkut
c) ( )Youtube
d) ( ) Twitter
e) ( )Blog
f) ( )Google
g) ( )MSN
h) ( )E-mail
i) Outros. Quais?

4. Você participaria de atividades disponíveis online desenvolvidas por nós, bolsistas do PIBID? 
Dossiê Especial: Experiências do PIBID na formação inicial e continuada de professores de línguas estrangeiras

HIBARINO \& NODARI (orgs)

Revista X, vol.1, 2015

ANEXO 2

Exemplo do gênero biografia: biografia do Ronaldo

Colégio Estadual Conselheiro Carrão - EFM

PIBID - UTFPR / $1^{\circ}$ ano $B$ - Inglês

\section{BIOGRAPHY}

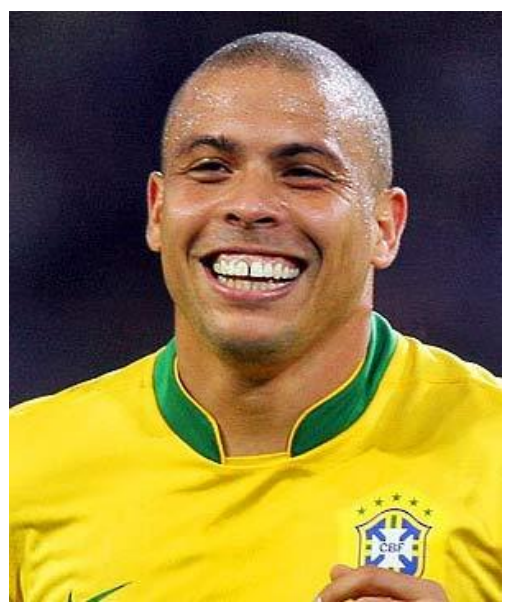

Ronaldo Luis Nazario de Lima was born in Rio de Janeiro on September 18, 1976 and he is a retired Brazilian footballer. He began playing futsal, a 5-on-5 soccer game that is extremely popular in Brazil and in other South American countries. He started playing football for the neighborhood Social Ramos Club, then São Cristóvão and Cruzeiro, this last when he was 17. He played as striker for Brazil and the Italian Serie $A$ club AC Milan. Ronaldo won three FIFA World Player of the Year awards (1996, 1997, 2002). Nicknamed "The Phenomenon", Ronaldo led the Brazilian team into the 1998 World Cup title match in France when he was 26. Ronaldo made his international career starting in Eindhoven (1994-1996), and playing in Barcelona (1996-1997), Inter Milan (1997 - 2002) Real Madrid (2002 - 2006), A. C. Milan (2007 - 2008). He won a lot of awards, and played for charity matches. Only injuries slowed Ronaldo -- serious knee injuries compromised his play at a relatively early age. After several comebacks, Ronaldo retired in 2011 when he was 34, he last played for Corinthians. He was named one of the top 11 soccer players of all-time by France. He was named by Pele as one of the 125 greatest footballers in March 2004. 
Dossiê Especial: Experiências do PIBID na formação inicial e continuada de professores de línguas estrangeiras

HIBARINO \& NODARI (orgs)

Revista X, vol.1, 2015

ANEXO 3

Enunciado da produção escrita - biografia

Colégio Estadual Conselheiro Carrão - EFM

PIBID - UTFPR - $1^{o}$ ano B - Inglês

Name:

Date:

\section{Biography}

Now you will write your autobiography. You should publish your text on Google Sites (https://sites.google.com/site/pibid1bconselheirocarrao/) or send it by e-mail pibidinglescarrao1b@gmail.com. Don't forget to put the key information about your life in your biography for your classmates and teachers know you better. Use the verbs in the "simple past" or "simple present" when necessary. 